\title{
RELATIONSHIP BETWEEN THE PHYSICAL PROPERTIES AND HAND OF JEAN FABRIC
}

\author{
Atsushi Kawamura', Chunhong Zhu², Julie Peiffer ${ }^{2}, K^{1}$ youngOk Kim³ ${ }^{3}, \mathrm{Yi} \mathrm{Li}^{4}$, Masayuki Takatera ${ }^{3 *}$ \\ 1Division of Textile and Kansei Engineering, Graduate School of Science and Technology, Shinshu University, 3-15-1 Tokida, Ueda, Nagano, 386-8567, Japan \\ ${ }^{2}$ Interdisciplinary Graduate School of Science and Technology, Shinshu University, 3-15-1 Tokida, Ueda, Nagano, 386-8567, Japan \\ ${ }^{3}$ Division of Kansei and Fashion Engineering, Institute for Fiber Engineering (IFES), Interdisciplinary Cluster for Cutting Edge Research (ICCER), Shinshu \\ University, 3-15-1 Tokida, Ueda, Nagano, 386-8567, Japan \\ ${ }^{4}$ Institute of Textile and clothing, The Hong Kong Polytechnic University, Hung Hom, Kowloon, Hong Kong \\ *takatera@shinshu-u.ac.jp
}

\begin{abstract}
:
We investigated the distinctive characteristics of jean fabrics (denim fabrics obtained from jeans) and compared the physical properties and the hand. We used 13 kinds of jean fabric from commercial jeans and 26 other fabric types. The physical properties were measured using the Kawabata evaluation system, and the fabric hand was evaluated by 20 subjects using a semantic differential method. To characterise the hand of jean fabrics compared with other fabrics, we used principal component analysis and obtained three principal components. We found that jean fabrics were characterised by the second principal component, which was affected by feelings of thickness and weight. We further characterised the jean fabrics according to 'softness \& smoothness' and 'non-fullness', depending on country of origin and type of manufacturer. The three principal components were analysed using multiple linear regression to characterise the components according to the physical properties. We explained the hand of fabrics including jean fabrics using its association with physical properties.
\end{abstract}

\section{Keywords:}

Fabric; Hand; Tactile; Physical Property; Jeans; Denim

\section{Introduction}

Denim is traditionally defined as a $3 / 1$ warp-faced twill fabric made from yarn-dyed warp and undyed yarn. Other weaves have been used more recently to produce lighter constructions [1]. Jean is defined as a 2/1 warp-faced twill fabric used chiefly for overalls or casual wear [1]. Denim and jean are not precisely distinguished between for practical uses. Typically, pants made using indigo denim are called blue jeans.

In Japan, denim is defined as a woven fabric with a twill or warp satin weave made of coloured warp yarn under 20s (30 tex), and bleached weft yarn or colour weft yarn that is finer than warp yarn. Jeans are defined as pants made of denim [2]. Blue jeans are very popular, and are a main fashion category.

Silhouette is the most important factor when purchasing jeans, and hand is also important [3]. Hand is a property or quality of fabric that corresponds to the tactile sensation, and is one deciding factor when purchasing clothing [4]. Thus, producers must satisfy consumer demands by analysing their product's hand.

Many researchers have considered the relationships between a fabric's physical properties and hand [5-10]. Measuring fabric hand has been a subject of textile research since the 1930s by Peirce [17]. The hand of fabric was predicted using mechanical properties of fabric such as tensile, bending, shear, compression and surface properties [18]. Theoretical models for bending of laminated fabrics to estimate hand have been investigated [19]. Characteristics of fabric hand for various kinds of textile were analysed [20]. Differences of tactile feeling between sensory tests touching by hand and skin were also investigated [21].

Regression formulas that predict the quantified fabric hand from physical properties have been proposed. These formulae are defined for each fabric category (e.g., summer and winter suit fabrics). However, there are no formulae for denim or jeans. Blue jeans are very popular, but their production has been decreasing in Japan. Thus, producers have attempted to increase the saleability and add value by considering the hand of jeans products.

Some researchers have investigated the effect of different washes or finishes on the tactile and mechanical properties of denim fabric [14-16]. However, the relationship between the physical properties and hand of jean fabrics has not been examined, and the characteristics of jean fabrics have not been compared to other fabrics.

In this study, we focussed on the fabric of jeans to understand its unique hand in comparison with other fabrics. We characterised the hand of fabrics cut from jeans products (jean fabric) and propose a formula for predicting the hand of a jean fabric from its physical properties. To understand hand of jeans will help manufacturers to make new hand of denim.

\section{Experimental}

We recorded some physical property measurements and hand evaluations of jean fabric, and of woven, knitted natural and 
kitted synthetic fibres for comparison. We determined the hand using two experiments.

Fabrics cut from jeans pants were prepared as samples because the hand changes when the product is fully finished. Table 1 shows the specifications of various fabrics and jean fabrics for each experiment. We investigated the characteristics

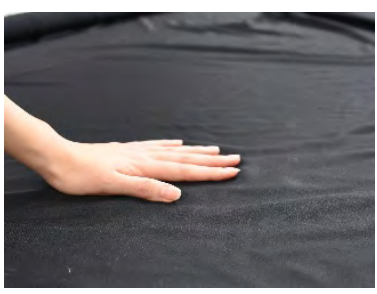

(a)

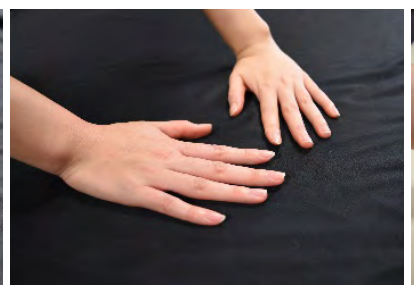

(b) of jean fabrics according to the country of origin and business condition. Products 4-1-4-4 were designed in the USA, Products 4-6 and 4-7 were Japanese, and products 4-5, and 4-8-4-13 were from speciality store retailers of private label apparel (SPA), which had relatively low prices. Samples 1-41 and 1-42 were raw fabrics.

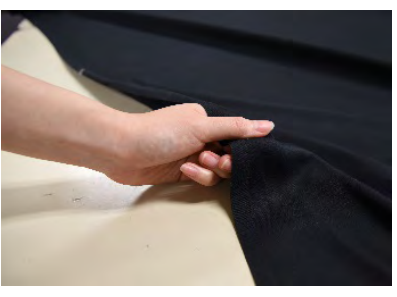

(c)

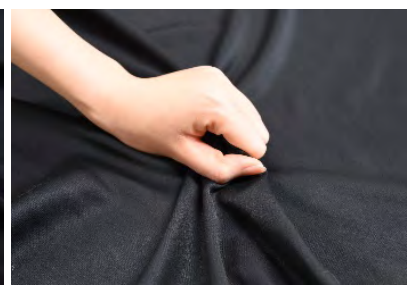

(d)

Figure 1. Touching methods for the first experiment: (a) initial contact; (b) stroking; (c) rubbing and pressing; and (d) squeezing

Table 1. Samples of experiment

\begin{tabular}{|c|c|c|c|c|c|c|c|}
\hline Experiment & Code & Composition & Fabric & Experiment & Code & Composition & Fabric \\
\hline 1 & $1-1$ & Cotton $100 \%$ & Plain woven & 2 & $1-21$ & Wool $100 \%$ & Plain woven \\
\hline 1 & $1-2$ & Linen $100 \%$ & Plain woven & 2 & $1-22$ & Wool $100 \%$ & Twill woven \\
\hline 1 & $1-3$ & Cotton $100 \%$ & Nonwoven & 2 & $1-23$ & Wool $100 \%$ & Satin woven \\
\hline 1 & $1-4$ & Cotton $100 \%$ & Denim woven & 2 & $1-31$ & $\begin{array}{l}\text { Rayon } 70 \% \text {, } \\
\text { polyester } 30 \%\end{array}$ & Twill woven \\
\hline 1 & $1-11$ & Polyester $100 \%$ & Chiffon woven & 2 & $1-41$ & Cotton $100 \%$ & $\begin{array}{c}\text { Denim woven } \\
2 / 1 \text { twill }\end{array}$ \\
\hline 1 & $1-13$ & Wool $100 \%$ & Satin woven & 2 & $1-42$ & $\begin{array}{c}\text { Cotton } 95 \% \text {, } \\
\text { polyurethane 5\% }\end{array}$ & $\begin{array}{c}\text { Denim woven } \\
3 / 1 \text { twill }\end{array}$ \\
\hline 1 & $1-15$ & $\begin{array}{l}\text { Polyester } 60 \% \text {, } \\
\text { wool } 40 \%\end{array}$ & Flannel woven & 2 & $4-1$ & Cotton $100 \%$ & $\begin{array}{l}\text { Denim woven } \\
3 / 1 \text { twill }\end{array}$ \\
\hline 1 & $2-1$ & $\begin{array}{l}\text { Cotton } 94 \% \text {, } \\
\text { elastane } 6 \%\end{array}$ & Rib knit & 2 & $4-2$ & Cotton $100 \%$ & $\begin{array}{c}\text { Denim woven } \\
3 / 1 \text { twill }\end{array}$ \\
\hline 1 & $2-4$ & $\begin{array}{l}\text { Viscose } 75 \% \text {, nylon } \\
15 \% \text {, elastane } 10 \%\end{array}$ & $\begin{array}{c}\text { Single jersey } \\
\text { knit }\end{array}$ & 2 & $4-3$ & Cotton $100 \%$ & $\begin{array}{c}\text { Denim woven } \\
3 / 1 \text { twill }\end{array}$ \\
\hline 1 & $2-7$ & $\begin{array}{c}\text { Cupro } 56 \% \text {, nylon } \\
24 \% \text {, elastane } 20 \%\end{array}$ & $\begin{array}{c}\text { Single jersey } \\
\text { knit }\end{array}$ & 2 & $4-4$ & Cotton $100 \%$ & $\begin{array}{c}\text { Denim woven } \\
3 / 1 \text { twill }\end{array}$ \\
\hline 1 & $2-9$ & $\begin{array}{l}\text { Tencel } 96 \% \text {, } \\
\text { elastane } 4 \%\end{array}$ & Jacquard knit & 2 & $4-5$ & Cotton $100 \%$ & $\begin{array}{c}\text { Denim woven } \\
3 / 1 \text { twill }\end{array}$ \\
\hline 1 & $2-14$ & $\begin{array}{c}\text { Polyester } 45 \%, \\
\text { nylon } 41 \%, \\
\text { elastane } 14 \%\end{array}$ & Jacquard knit & 2 & $4-6$ & $\begin{array}{c}\text { Cotton } 99 \% \text {, } \\
\text { polyurethane } 1 \%\end{array}$ & $\begin{array}{l}\text { Denim woven } \\
\text { 3/1 Twill }\end{array}$ \\
\hline 1 & $2-20$ & $\begin{array}{l}\text { Nylon } 95 \% \text {, } \\
\text { elastane } 5 \%\end{array}$ & $\begin{array}{c}\text { Single jersey } \\
\text { knit }\end{array}$ & 2 & 4-7 & $\begin{array}{c}\text { Cotton } 95 \% \text {, } \\
\text { polyurethane 5\% }\end{array}$ & $\begin{array}{c}\text { Denim Woven } \\
3 / 1 \text { twill }\end{array}$ \\
\hline 1 & $2-22$ & $\begin{array}{c}\text { Polyester } 89 \% \text {, } \\
\text { spandex } 11 \%\end{array}$ & Knit & 2 & $4-8$ & $\begin{array}{c}\text { Cotton } 98 \% \text {, } \\
\text { polyurethane } 2 \%\end{array}$ & $\begin{array}{c}\text { Denim woven } \\
3 / 1 \text { twill }\end{array}$ \\
\hline 1 & $3-1$ & Silk $100 \%$ & $\begin{array}{c}\text { Jacquard } \\
\text { woven }\end{array}$ & 2 & $4-9$ & Cotton $100 \%$ & $\begin{array}{c}\text { Denim woven } \\
3 / 1 \text { twill }\end{array}$ \\
\hline 1 & $3-2$ & Silk $100 \%$ & $\begin{array}{l}\text { Jacquard } \\
\text { woven }\end{array}$ & 2 & $4-10$ & Cotton $100 \%$ & $\begin{array}{l}\text { Denim woven } \\
3 / 1 \text { twill }\end{array}$ \\
\hline 1 & $3-5$ & Silk $100 \%$ & $\begin{array}{l}\text { Jacquard } \\
\text { woven }\end{array}$ & 2 & $4-11$ & Cotton $100 \%$ & $\begin{array}{c}\text { Denim woven } \\
3 / 1 \text { twill }\end{array}$ \\
\hline 1 & $3-12$ & Silk $100 \%$ & $\begin{array}{l}\text { Jacquard } \\
\text { woven }\end{array}$ & 2 & $4-12$ & Cotton $100 \%$ & $\begin{array}{c}\text { Denim woven } \\
3 / 1 \text { twill }\end{array}$ \\
\hline 1 & $3-13$ & Silk $100 \%$ & $\begin{array}{l}\text { Jacquard } \\
\text { woven }\end{array}$ & \multirow{2}{*}{2} & \multirow{2}{*}{$4-13$} & \multirow{2}{*}{ Cotton $100 \%$} & \multirow{2}{*}{$\begin{array}{c}\text { Denim woven } \\
3 / 1 \text { twill }\end{array}$} \\
\hline 1 & $3-18$ & Silk $100 \%$ & $\begin{array}{l}\text { Jacquard } \\
\text { woven }\end{array}$ & & & & \\
\hline
\end{tabular}




\subsection{First experiment: sensory evaluation of various fabrics}

The first experiment was carried out on various fabrics. We used a semantic differential method. Subjects touched fabrics freely using four touching methods: initial contact, stroking, rubbing and pressing and squeezing, as shown in Fig. 1. We evaluated the 16 factors in Table 2 on a seven-point scale (from -3 to 3 ), and considered the 20 fabric samples (1-1-3-18) shown in Table 1. Our experiments were carried out at room temperature (i.e., at $21 \pm 1^{\circ} \mathrm{C}$ with $65 \pm 2 \%$ relative humidity). The samples were preconditioned for 24 hours. Twenty Japanese university students (10 males and 10 females) were used as volunteers. They washed their hands and wiped off water droplets before the experiment started. At first, the subjects rested for 30 minutes, then they started to touch fabrics.

\subsection{Second experiment: sensory evaluation of 15 denim fabrics and 4 various fabrics}

The second experiment was mainly carried out on jean fabrics cut from on-sale jean pants. We used the same semantic differential method, with subjects evaluating the fabric surface by the 'rubbing and pressing', and 'squeezing' methods shown in Figure. 1(c) and (d). We used the same evaluations as the first experiment, and conducted the evaluations at a temperature of $20^{\circ} \mathrm{C} \pm 1^{\circ} \mathrm{C}$ and a relative humidity of $65 \pm 2 \%$. The samples were pre-exposed at least 24 hours before the experiment. Japanese university students were the participants in this experiment (10 males and 10 females, not participants in the first experiment). The experiment steps were same as in the first experiment. They evaluated the 19 samples in Table 1.
We used the squeeze method because the results of the first experiment suggested that it was the most appropriate.

\subsection{Measurements of the fabrics' physical properties}

We measured the physical properties of all 39 fabrics using the Kawabata evaluation system for fabric (Kato Tech Co., Ltd, KES-FB system). We considered the compression, surface, bending, shearing, tensile, thermal and air permeability properties of each fabric. The descriptors and symbols of the fabric properties are shown in Table 3 . The experiments were carried out five times for each property and sample. We calculated the mean values for all the results depending on the direction and surface side of the measurement. The experimental environment and setup was the same as for the previous experiments.

We compared the measurements with the results of the sensory evaluation tests.

\section{Results and discussion}

The results for fabrics 1-3 were removed because we could not measure the tensile load. We performed a principal component analysis (PCA) to identify hidden patterns in the hand data.

Our analysis showed that the first three principal components had a high cumulative contribution ratio of $88.2 \%$. Thus, we used these components to analyse the hand of the fabric. The principal component loadings are shown in Figures 2-4. The

Table 2. Evaluation factors for the first and second experiments

\begin{tabular}{|c|c|}
\hline Evaluation factors & Explanations \\
\hline Cool-warm & At relatively low/high temperature. \\
\hline Damp-dry & Slightly wet as with steam, suspended vapour, dew or mist. \\
\hline Itchy-non itchy & Affected by itching. \\
\hline $\begin{array}{c}\text { Scratchy-non } \\
\text { scratchy }\end{array}$ & Executed using a pen or brush: scratches, as opposed to bold, firm lines. \\
\hline Prickle-non prickle & Causes a prick or puncture. \\
\hline Rough-smooth & Having a surface free from projections and irregularities. \\
\hline Sticky-non adhesive & Having a sticky or adhering property. \\
\hline Stiff-pliable & Rigid; not flexible or pliant. \\
\hline Thick-thin & Having relatively little extension between opposite surfaces. \\
\hline Hard-soft & Presenting a yielding surface to the touch; not offering absolute resistance to pressure. \\
\hline Inelastic-elastic & Spontaneously resumes its normal shape after being dilated by external force. \\
\hline $\begin{array}{l}\text { Non fullness- } \\
\text { fullness }\end{array}$ & Spontaneously resumes its normal bulk after being contracted by external force. \\
\hline Heavy-light & Weight of fabric. \\
\hline
\end{tabular}


first principal component load was affected by the fabric softness (i.e., 'rough-smooth', 'prickle-non prickle', 'stiff-pliable', 'sticknon adhesive', or 'damp-dry'), so we called this component 'softness and smoothness'. The second principal component load was affected by the thickness and weight ('thick-thin' and 'heavy-light'), so we called it 'lightness and thinness'. The third principal component load was affected by the fullness of the fabric ('cool-warm' and 'non-fullness-fullness'), so we called it 'non-fullness'.

Figures 5-7 plot the principal component scores for the different fabrics. We can see that the fabrics are clustered according to their structure and material. Denim fabrics (including jean fabrics) were characterised as being thick and heavy by the second principal component, as shown in Figure 5. Furthermore, jean fabrics were characterised in detail by the first principal component. The raw and USA jean fabrics were characterised as being hard and rough, but the SPA and
Japanese jean fabrics were characterised as being soft and smooth. The jean fabrics were roughly grouped by the third principal component, as shown in Figure 6. The fabric types were characterised by fullness in order of raw, USA, Japanese and SPA, as shown in Figure 7.

We ran a multiple regression analysis to objectively characterise the jean fabrics using the principal components as objective variables and the physical properties as explanatory variables. Before applying the multiple regression analysis, we calculated and compared the correlation coefficients between the principal components and the value and logarithm of each physical property. As a result, the correlation coefficients for the logarithms were less than those of the raw values, so we used the raw values in our analysis. The bending and shearing properties for the raw denim fabrics were outliers with high correlation coefficients, so we did not include these fabrics in our multiple regression analysis. When analysing the second

Table 3. Measurements of the physical properties

\begin{tabular}{|c|c|c|c|c|c|c|c|}
\hline \multirow{2}{*}{$\begin{array}{c}\text { Blocked } \\
\text { properties }\end{array}$} & \multirow{2}{*}{ Symbols } & \multirow{2}{*}{$\begin{array}{c}\text { Characteristic } \\
\text { value }\end{array}$} & \multirow{2}{*}{ Unit } & \multicolumn{4}{|c|}{$\begin{array}{c}\text { Direction and surface side in } \\
\text { measurement }\end{array}$} \\
\hline & & & & Warp & Weft & Face & Back \\
\hline \multirow{4}{*}{ Tensile } & EM & Tensile strain & $\%$ & \multirow{4}{*}{$\circ$} & \multirow{4}{*}{$\circ$} & & \\
\hline & LT & Linearity & - & & & & \\
\hline & WT & Tensile energy & $\mathrm{gf} \cdot \mathrm{cm} / \mathrm{cm}^{2}$ & & & & \\
\hline & RT & Resilience & $\%$ & & & & \\
\hline \multirow{2}{*}{ Bending } & $\mathrm{B}$ & Bending rigidity & $\mathrm{gf} \cdot \mathrm{cm}^{2} / \mathrm{cm}$ & \multirow{2}{*}{$\circ$} & \multirow{2}{*}{$\circ$} & & \\
\hline & $2 \mathrm{HB}$ & Hysteresis & $\mathrm{gf} \cdot \mathrm{cm} / \mathrm{cm}$ & & & & \\
\hline \multirow{3}{*}{ Shearing } & G & Shear stiffness & $\begin{array}{c}\mathrm{gf} / \\
\mathrm{cm} \cdot \text { degree }\end{array}$ & \multirow{3}{*}{$\circ$} & \multirow{3}{*}{$\circ$} & & \\
\hline & $2 \mathrm{HG}$ & $\begin{array}{c}\text { Hysteresis at } \varphi= \\
0.5^{\circ}\end{array}$ & $\mathrm{gf} / \mathrm{cm}$ & & & & \\
\hline & $2 \mathrm{HG} 5$ & Hysteresis at $\varphi=5^{\circ}$ & $\mathrm{gf} / \mathrm{cm}$ & & & & \\
\hline \multirow{4}{*}{ Compression } & $\mathrm{T}_{\mathrm{o}}$ & Thickness & $\mathrm{mm}$ & \multirow{7}{*}{$\circ$} & \multirow{7}{*}{$\circ$} & & \\
\hline & LC & Linearity & - & & & & \\
\hline & WC & $\begin{array}{c}\text { Compressional } \\
\text { energy }\end{array}$ & $\mathrm{gf} \cdot \mathrm{cm} / \mathrm{cm}^{2}$ & & & & \\
\hline & $\mathrm{RC}$ & Resilience & $\%$ & & & & \\
\hline \multirow{3}{*}{ Surface } & MIU & Coefficient of friction & - & & & \multirow{3}{*}{$\circ$} & \multirow{3}{*}{ ○ } \\
\hline & MMD & $\begin{array}{l}\text { Mean deviation of } \\
\text { MIU }\end{array}$ & - & & & & \\
\hline & SMD & $\begin{array}{l}\text { Geometrical } \\
\text { roughness }\end{array}$ & micron & & & & \\
\hline \multirow[b]{2}{*}{ Thermal } & qmax & Warm/Cool feeling & $\mathrm{W} / \mathrm{m}^{2}$ & & & \multirow[b]{2}{*}{$\circ$} & \multirow[b]{2}{*}{$\circ$} \\
\hline & $\mathrm{K}$ & $\begin{array}{l}\text { Constant thermal } \\
\text { conductivity }\end{array}$ & 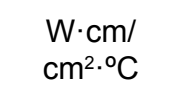 & & & & \\
\hline $\begin{array}{c}\text { Air } \\
\text { permeability }\end{array}$ & $\mathrm{R}$ & $\begin{array}{l}\text { Permeating } \\
\text { resistance }\end{array}$ & $\mathrm{kPa} \square \mathrm{s} / \mathrm{m}$ & & & $\circ$ & $\circ$ \\
\hline Construction & W & Weight & $\mathrm{mg} / \mathrm{cm}^{2}$ & & & & \\
\hline
\end{tabular}




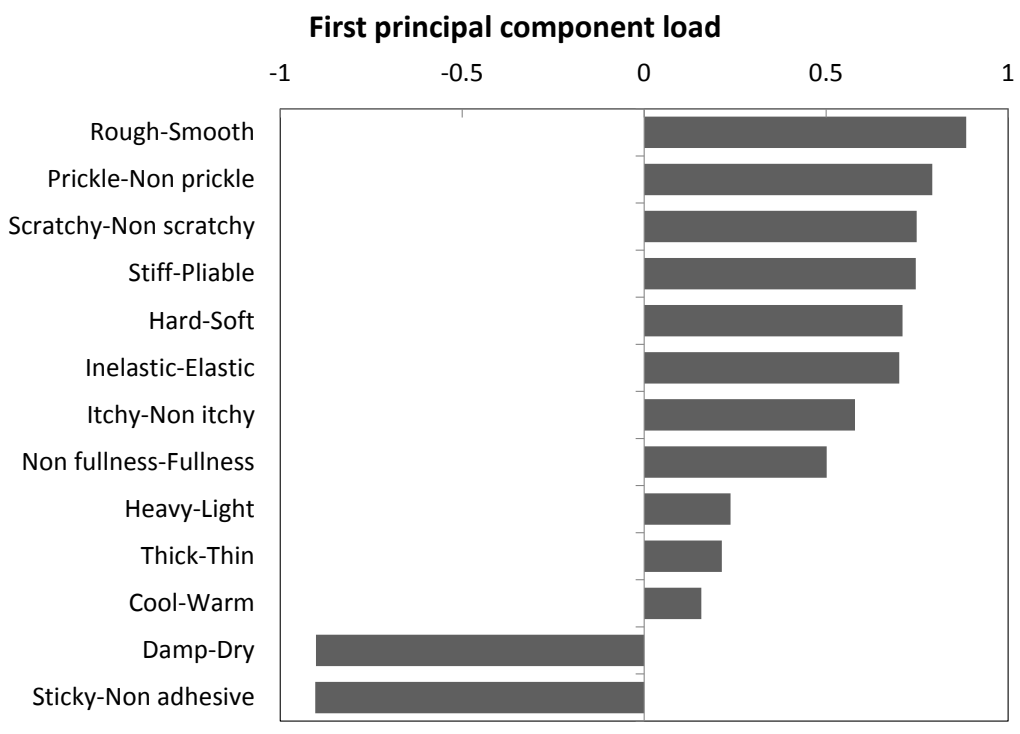

Figure 2. First principal component load of the sensory evaluation results.

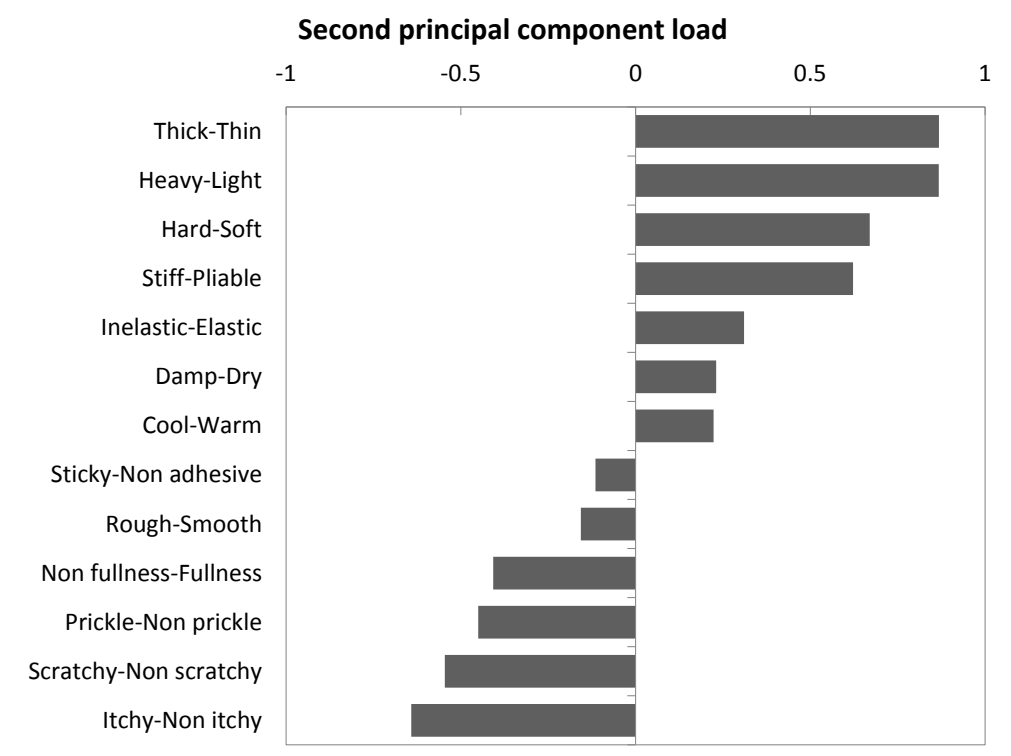

Figure 3. Second principal component load of the sensory evaluation results.

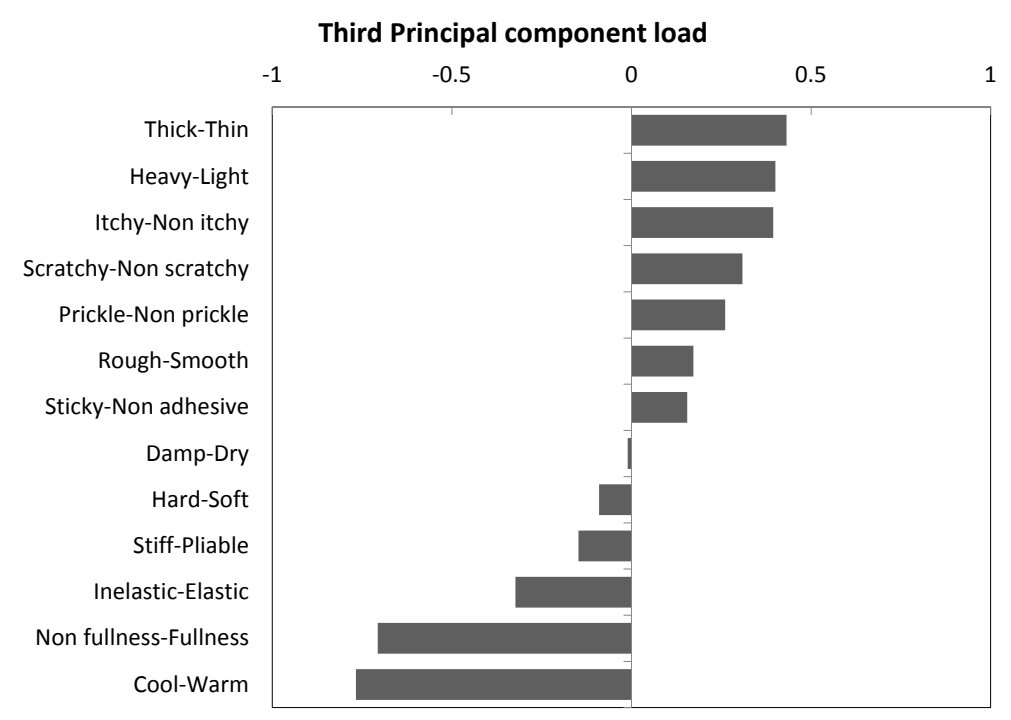

Figure 4. Third principal component load of the sensory evaluation results. 


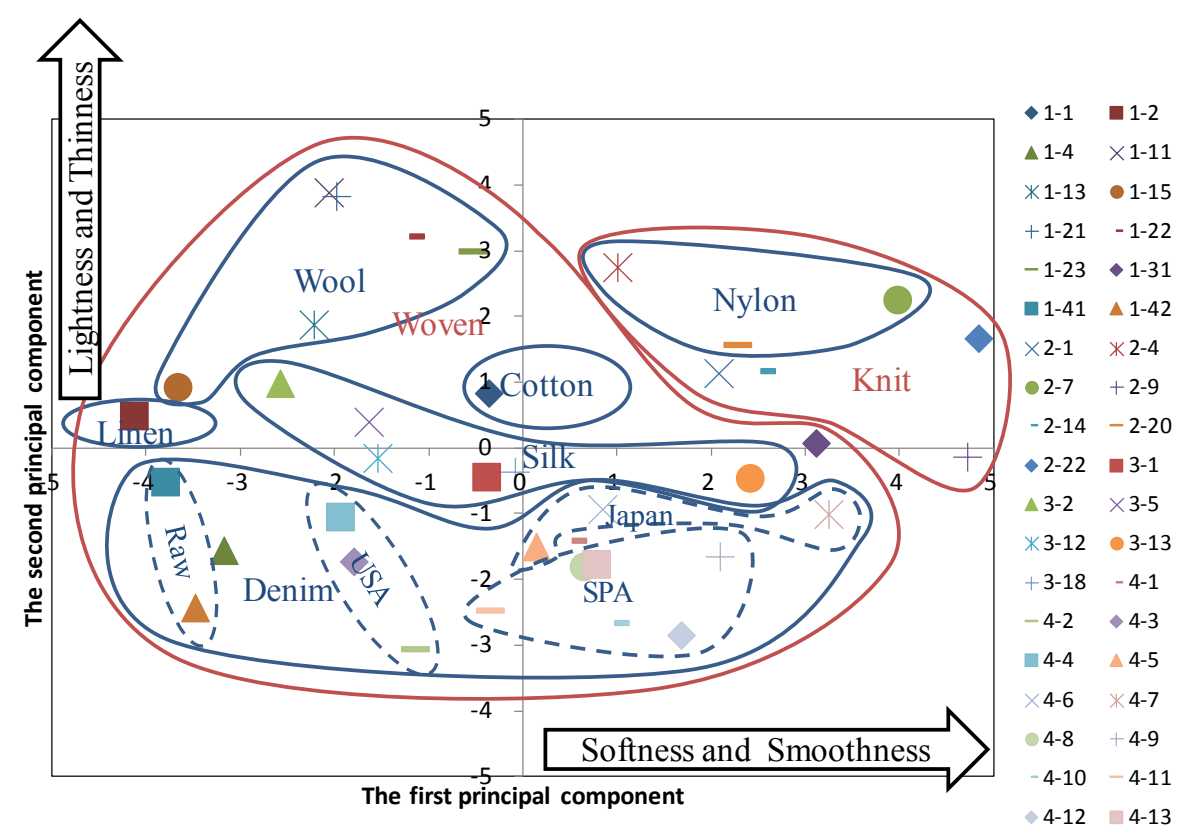

Figure 5. Sample plot using the first and second principal component scores of the sensory evaluation results.

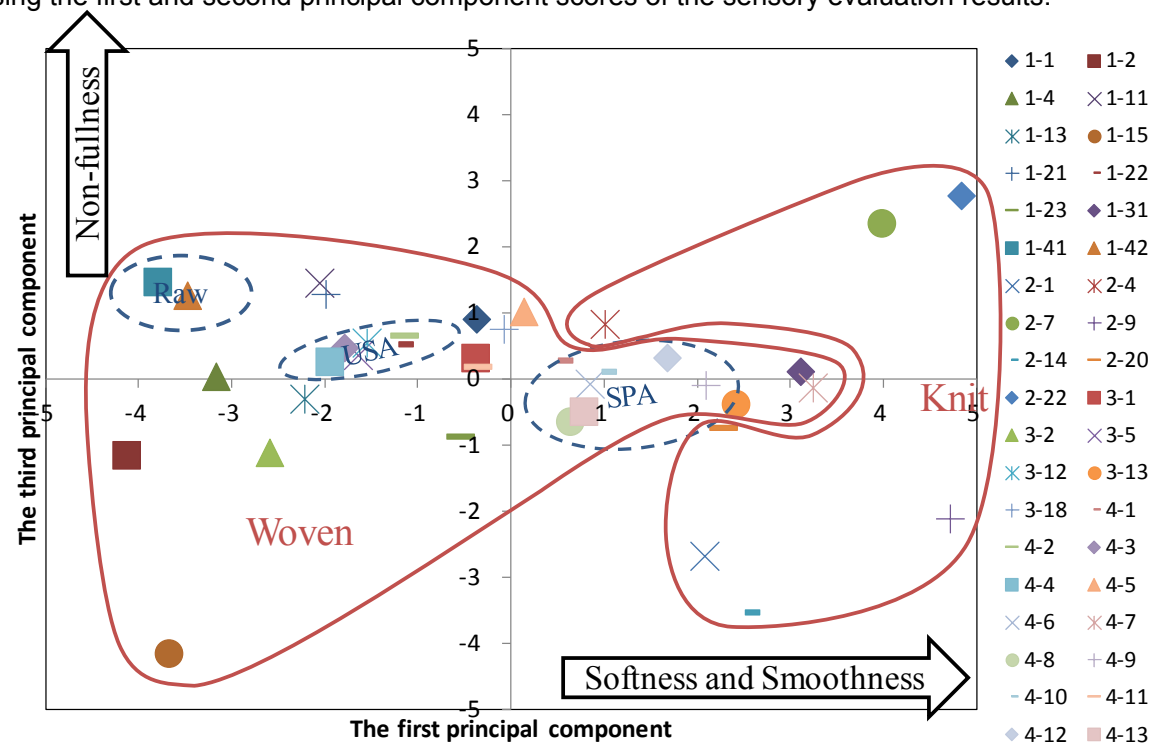

Figure 6. Sample plot using the first and third principal components of the sensory evaluation results

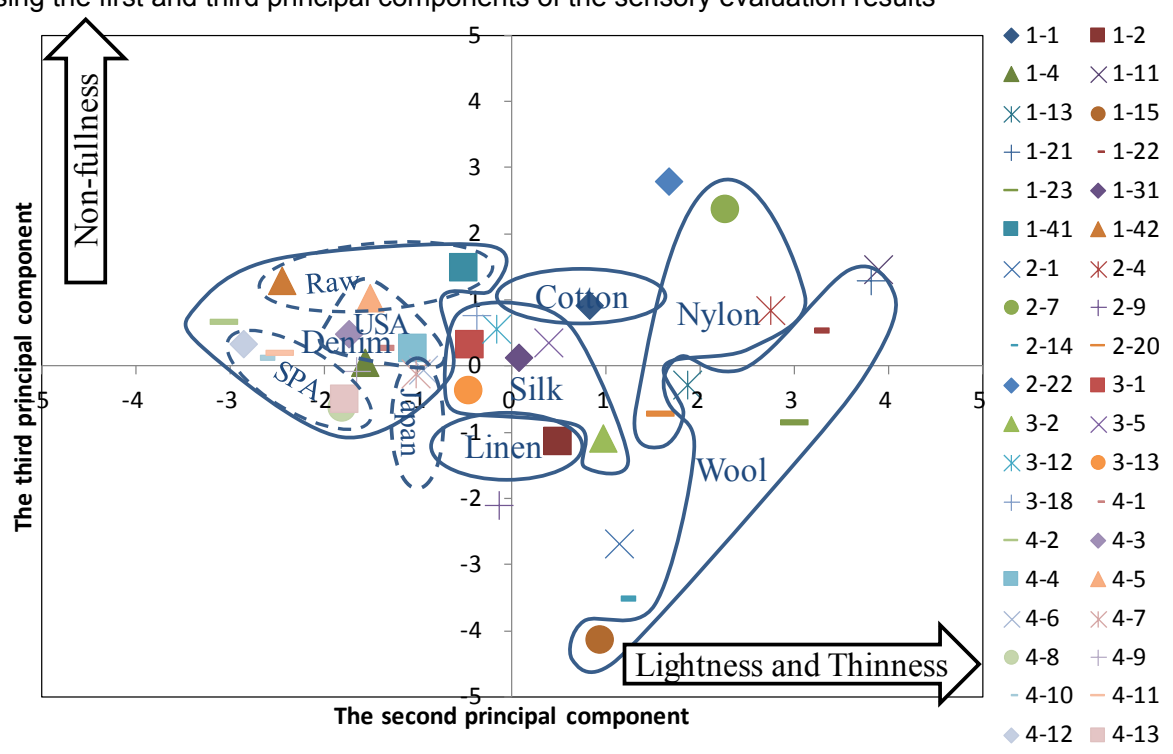

Figure 7. Sample plot using the second and third principal components of the sensory evaluation results 
principal component, we detected some multicollinearity between T0 and $\mathrm{K}$. Excluding T0 increased the correlation coefficient, so we excluded it from our analysis.

The multiple regression equations for each principal component are:

- First principal component $=-6.4296+0.3700 \times \mathrm{R}+0.3217$

$\times$ qmax $+0.6701 \times \mathrm{EMT}+0.3502 \times \mathrm{MMD}+0.2638 \times \mathrm{MIU}$

(1)

- Second principal component $=6.5460-0.4503 \times \mathrm{W}-0.2903$

$\times \mathrm{R}-0.3382 \times \mathrm{MIU}+0.2347 \times \mathrm{RC}$

- Third principal component $=-4.4395+0.8722 \times$ qmax -0.6073

$\times \mathrm{EMT}+0.4274 \times \mathrm{G}+0.3935 \times \mathrm{LC}$

The predicted results and experimental values from the sensory tests are shown in Figure 8-10. The jean fabrics are plotted using a different character than the other fabrics. The adjusted R2 value for Equation (1) was 0.6265 , for Equation (2) was 0.8654 and for Equation (3) was 0.7315. Their significance levels were less than $1 \%$, so they were significant.

The first principal component depends on MIU, MMD, EMT, qmax, and R. MIU and MMD describe 'rough-smooth' feelings. $R$ is the air permeability resistance and depends on the fabric density. So it may affect the 'stiff-pliable' feeling. EMT is the tensile strain under a specified load and represents the ability of a fabric to deform. Thus, EMT follows the hand movement and affects the 'stick-non adhesive' feeling. The second principal component depends on RC, MIU, R and W. W describes the 'heavy-light' feeling without T0, and $\mathrm{W}$ and $\mathrm{RC}$ are indirectly related to the thickness. The third principal component depends on LC, G, EMT and qmax. LC describes the 'non-fullness-fullness' feeling and qmax describes the 'cool-warm' feeling. The jean fabrics' results are in the middle in terms of the first and third principal components, as shown in Figures 8 and 10. However, they are lower than the other fabrics in terms of the second principal component, as shown in Figure 9. Thus, the second principal component represents the main characteristics of jean fabrics.

The principal components of the results of the sensory test depend on certain physical properties. qmax affects the first and third principal component. However, thermal properties were not considered in the previous studies [5-10]. It was reported that qmax affects tactile sensations or shittori (the Japanese word for smoothness accompanied with either a warm or soft feeling) [11-12]. Researchers have previously found that thermal properties have an effect on fabric hand [13]. In this study, we found that qmax affects both the first and third principal components of fabric hand, which confirms that thermal properties affect the hand of fabrics.

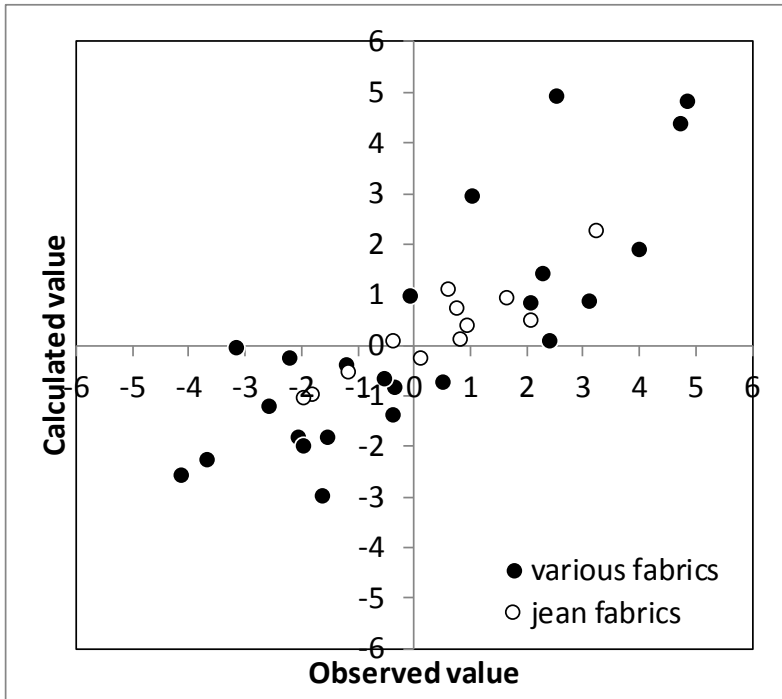

Figure 8. Scatter plot of the theoretical and observed values of the first principal component.

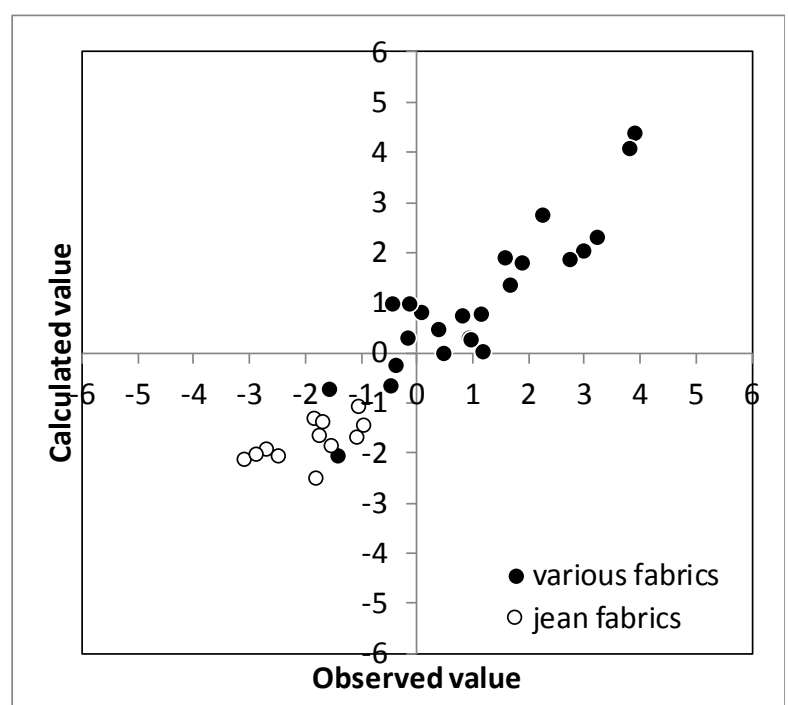

Figure 9. Scatter plot of the theoretical and observed values of the second principal component.

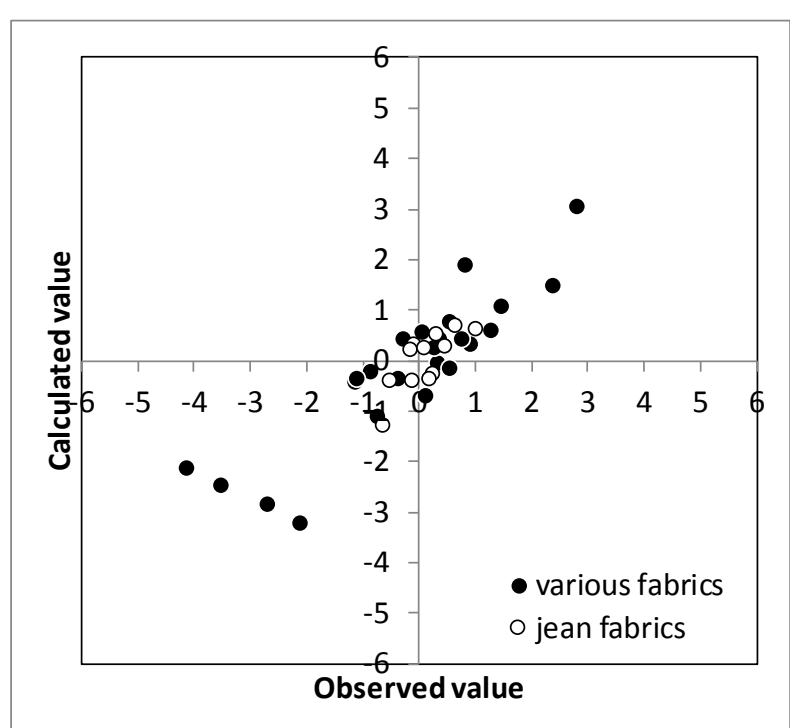

Figure 10. Scatter plot of the theoretical and observed values of the third principal component. 


\section{CONCLUSIONS}

We have characterised jean fabrics as being thicker and heavy than other fabrics using the principal component analysis of hand. The jean fabrics were characterised in detail according to 'softness \& smoothness' and 'non-fullness'. In the first principal component ('softness \& smoothness'), the jean fabrics were characterised in order of raw, USA, Japanese and SPA. Raw and USA fabrics were hard and rough, but the Japanese and SPA fabrics were soft and smooth. Fabrics can be roughly divided into being from the USA, SPA or Japan using the third principal component ('non-fullness').

We used multiple regression analysis to objectively characterise the jean fabrics using the principal components scores as objective variables and the physical properties as explanatory variables. These results could be used to find the position of new jean fabrics with a different hand. Manufacturers also can make new hand of denim by controlling the physical properties related to the hand.

\section{ACKNOWLEDGEMENTS}

This work was supported by Japan Society for the Promotion of Science KAKENHI grant number 24220012.

\section{References}

[1] Mclntyre JE, Daniels BA. Textile Terms and Definitions, Tenth Edition. The Textile Institute, 1997, 94, 175.

[2] Japanese Standards Association. JIS HandBook 31 Textiles, JISL0206, JISL0208, JISL0215, 2003, 106, 141, 214.

[3] The Senken Shimbun Company. Senken Shimbun, 21/9/2012, 7.

[4] Behery H. (2005) Effect of mechanical and physical properties on fabric hand. Woodhead Publishing Limited, 46.

[5] Kawabata S. (1980) The standardization and analysis of hand evaluation, 2nd edition, Textile Machinery Society of Japan, Osaka.

[6] Kawabata S, Niwa M. (1984) Improvement in the Objective Evaluation of Fabric Hand for Thin Dress Fabrics, Part 1. Selection of the Fabric Deformation Range in the Measurement of Mechanical Properties. Journal of the Textile Machinery Society of Japan, 37, 45-53.

[7] Sakaguchi H, Kawabata S, Niwa M. (1986) A Development in the Objective Measurement of the Quality of Knitted Fabrics Used for Underwear, Part1. Measurement of the Fabric-Characteristics. Journal of the Textile Machinery Society of Japan, 39, 33-42.
[8] Matsudaira M, Kawabata S, Niwa M. (1984) Measurements of Mechanical Properties of Thin Dress Fabrics for Hand Evaluation. Journal of the Textile Machinery Society of Japan, 37, 41-49.

[9] Kawabata S, Niwa M. (1980) Formulas $K N-101$ and $K N$ 201 for the Translation of Basic Mechanical Properties of Fabric into Hand Values and KN-301 from the Hand Values into Total Hand Value. Journal of the Textile Machinery Society of Japan, 33, 30-35.

[10] Sakaguchi H, Kawabata S, Niwa M. (1986) A Development in the Objective Measurement of the Quality of Knitted Fabrics Used for Underwear, Part2. Equations for the Quality Measurement. Journal of the Textile Machinery Society of Japan, 39, 43-50.

[11] Sukigara S. (2008) Towards the Comfortable Tactile Sensation, "Shittori" and "Numeri" for Fabric Hand. Sen'i Gakkaishi, 64, 404-408.

[12] Tanaka Y, Sukigara S. (2008) Evaluation of "Shittori" Characteristic for Fabrics. Journal of Textile Engineering, 54, 75-81

[13] Liao X, Li Y, Hu J, Wu X, Li Q. (2014) A Simultaneous Measurement Method to Characterize Touch Properties of Textile Materials. Fibers and Polymers, 15, 1548-1559.

[14] Halleb, Naima Abdelfattah, Mehdi Sahnoun, and Mourched Cheikhrouhou. (2015) The effect of washing treatments on the sensory properties of denim fabric, Textile Research Journal, 85.2 150-15

[15] Card A, Moore MA and Ankeny M. (2006) Garment washed jeans, impact of laundering on physical properties. Int $J$ Clothing Sci Technol, 18, 43.

[16] Tarhan M and Sariisik M. (2009) A comparison among performance characteristics of various denim fading processes, Text Res J, 79, 301.

[17] Peirce FT. The handle of cloth as a measurable quality. $J$ Textile Inst 1930; 21: 337-416.

[18] Ciesielska-Wrobel, I. L., and Van Langenhove, L. (2012). The hand of textiles- definitions, achievements, perspectives- a review. Text Res J, 82(14), 1457-1468.

[19] Dawes, Vivienne H., and J. D. Owen. (1972) The handle and bending behaviour of fabric laminates, $J$ Textile Inst. 63(8), 443-474.

[20] Matsudaira M and Matsui M (1992). Features of mechanical properties and fabric handle of silk weaves. J Textile Inst. 83(1), 133-143.

[21] Li YN, M Kamijo, and H Yoshida (2015). Effectiveness of the "Tezawari" and "Hadazawari" sensory test methods in the evaluation of fine-textured knitted fabrics Part I: Coolness and moistness discrimination. Text Res J DOI: 0040517514566089. 